\title{
COVID-19: A Comprehensive Overview
}

Hira Amir, MD and Ally PH Prebtani, BScPhm, MD, FRCPC

\section{About the Authors}

Hira Amir is a medical graduate currently working as a research volunteer at McMaster University.

Ally PH Prebtani is with the Division of Endocrinology \& Metabolism, Department of Medicine, McMaster University

Submitted: April 20, 2020. Accepted June 20, 2020. Published: July 2, 2020. Ahead of issue. DOI: 10.22374/cjgim.v15i3.462

\begin{abstract}
Coronaviruses are important pathogens reported in humans and animals. A novel coronavirus, formally known as Severe Acute Respiratory Syndrome Coronavirus 2 (SARS-CoV-2), was identified as a cause of pneumonia cases in Wuhan, China, in late 2019. Since its outbreak in China, it has disproportionately affected many countries. Coronavirus disease 2019 (COVID-19) was officially declared a pandemic on March 11,2020 and remains a global concern. A spectrum of disease severity has been reported with a variable course of illness from mild upper respiratory symptoms, pneumonia to acute respiratory distress syndrome (ARDS), shock, multiorgan dysfunction and death. The worldwide dissemination of the virus justifies the global efforts in identifying potential treatment strategies and a vaccine for improved clinical and long-term outcomes. This article will reflect on human viral replication and transmission, variable clinical presentation, assessment, treatment and discussion of complications. Isolation precautions according to infection prevention and control including protective apparel will be discussed with emphasis on criteria for discontinuation of transmission precaution.
\end{abstract}

\section{Methods}

We carefully conducted a literature review for the pathogenesis, microbiology, clinical presentation, diagnosis and available effective management and prevention options for COVID 19. The articles for review were primarily retrieved from UpToDate, WHO, PubMed, Elsevier, Medscape and peer-reviewed journal articles including The New England Journal of Medicine (NEJM), Journal of American Medical Association (JAMA), The Lancet, and Canadian Medical Association Journal (CMAJ) using 'COVID 19', 'SARS-CoV2', and 'Human Coronavirus' as keywords for our search. Most articles were dated between January to April 2020. We screened the references provided in most publication to avoid errors of missing publications. We restricted our search to publications in English and excluded abstracts from conferences and observations.

\section{Virology and Pathogenesis}

The coronavirus belongs to a family within Nidovirale order that uses nested set of mRNAs to replicate. Human coronavirus is from two of the four genera of virus family: alpha and beta coronaviruses. ${ }^{1}$ The pathogen, which is a beta coronavirus, is similar to SARS (Severe Acute Respiratory Syndrome) and MERS (Middle Eastern Respiratory Syndrome). ${ }^{1}$ The Angiotensin Converting Enzyme 2 (ACE2) receptor appears important for viral entry into the pneumocytes. ${ }^{2}$ It is known to mutate and combine rapidly, serving as an ongoing challenge to our understanding of disease spectrum and patient management (Figure 1).

\section{Viral Transmission}

The respiratory pathogen was initially thought to have a zoonotic transmission, however, currently its main mode of transmission remains person-to-person via respiratory droplets (more than 5-10 micrometers in diameter which travel less than 2 meters or 6 feet), resembling the spread of influenza. ${ }^{4,5}$ In certain circumstances, transmission via aerosol droplets less than 5 micrometers in diameter which may travel more than 2 metres or 6 feet is possible in aerosol-generating medical procedures, 


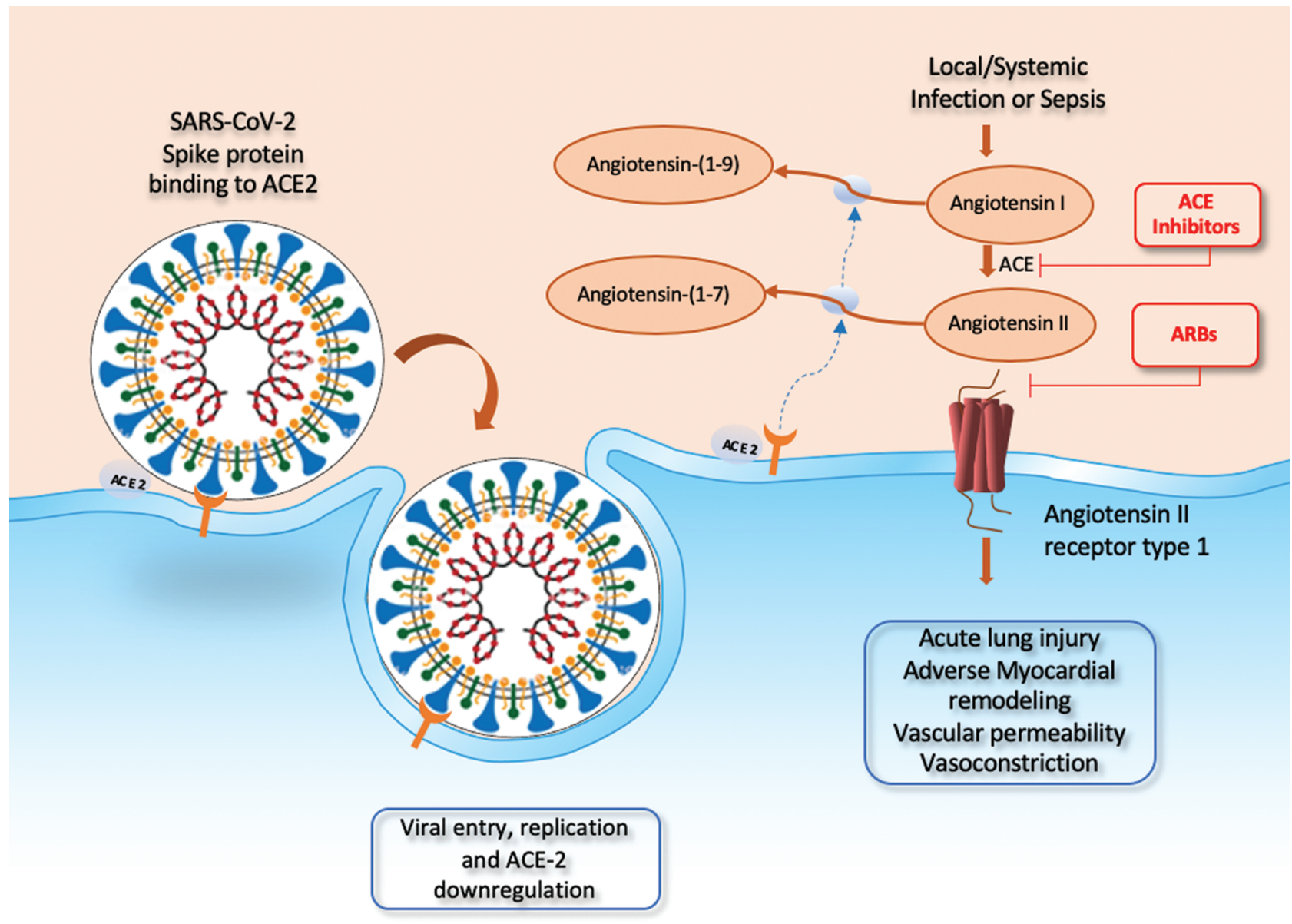

Figure 1. Interaction between SARS-CoV-2 and the Renin-Angiotensin-Aldosterone System.

Adapted from: The New England Journal of Medicine (NEJM) ${ }^{3}$

which in turn necessitates the use of enhanced personal protective equipment (PPE) and dual transmission precautions (contact and airborne) to reduce contagion rate. ${ }^{4}$ Fecal-oral transmission remains insignificant in the spread of the infection. ${ }^{5}$

The viral incubation period, which is the time of viral exposure to symptom development, is found to be 2 weeks after exposure with varying time of symptom onset but usually between 2-5 days. This phase, also referred to as 'pre-symptomatic' or "asymptomatic" phase, and is known to be contagious for some individuals due to increased viral shedding in the upper respiratory tract even before development of significant symptoms. ${ }^{6}$ This necessitates mass testing of high-risk population such as residents or caregivers of residents in LTC facilities, group homes, retirement homes and other places where there are mass numbers living under one dwelling. ${ }^{7}$ The proposed testing approach will allow proper isolation of infected individuals (symptomatic and pre or asymptomatic) and quarantine those that are exposed, ultimately severing the chain of infection spread especially in those that are at elevated risk for the infection.

\section{Factors for Viral Transmission}

Longer incubation period and pre-symptomatic viral shedding contribute to rapid viral dissemination with COVID-19. Another feature that helps quantify the transmission rate is the basic viral reproductive number (R). It is the median number of new infections that result from a single infected person in a susceptible group. An R below 1 indicates that an outbreak is declining rather than growing, explained by the fact that each infected individual will transmit/infect less than one person in that community. Alternatively, higher Ro means more people get infected before the end of this pandemic. It is difficult to have a precise Ro, as it fluctuates with various factors such as contact with people, physical distancing and measures like lockdowns to mitigate the viral spread. ${ }^{8}$ 
Another parameter is the effective reproductive number ( $\mathrm{R} e$ ), which is comparable to $\mathrm{R}$ but not fully dependant on the vulnerable population. $\mathrm{R}$ is not altered by immunity against a viral infection either by vaccination or natural infection but immunity in the given population can impact Re. Having said that population immunity can successfully shrink the outbreak if the $\mathrm{R} e$ is below $1 .^{9}$

Depending on these factors and possible measures to control viral dissemination, COVID 19 cases may appear in waves with perhaps distinct intervals shown in the Figure 2 (see Figure 1 in the link).

\section{Disease Spectrum}

Patients with COVID-19 may present with a range of clinical manifestations, initially mild respiratory tract symptoms, which may progress to pneumonia and severe disease. The latter may result in complications like sepsis with multiorgan dysfunction and respiratory failure, requiring advanced oxygenation and ventilation with hemodynamic support.

\section{Prevention and Treatment}

Given the present situation, isolation precautions such as droplet precautions are recommended in most situations depending upon degree of interaction with a COVID-19 patient. Airborne precautions are recommended in special circumstances where aerosolization is more than in usual situations such as aerosolgenerating medical procedures (AGMPs). ${ }^{10,11}$

To date there has been no approved, effective, and safe pharmacologic and/or preventive treatment, including vaccines, for COVID 19 with the exception of Remdesivir for emergency use in severe illness in United States. Several drugs are undergoing clinical and human trials and may be considered as potential therapies for treatment of COVID 19 in the future with ongoing efforts for vaccine development.

\section{Clinical Picture}

The COVID-19 illness has a variable presentation ranging from an asymptomatic form, mild pneumonia to a severe or critical form of the disease. Approximately $15 \%$ of the individuals with clinically evident infection develop severe form of the disease, with an overall case fatality rate from 1-14\% which varies with time, region, comorbidities, age and accurate reporting of data. ${ }^{12}$

Common symptoms include fever, dry cough, myalgias, anorexia and fatigue, not explained by a pre-existing medical condition. ${ }^{13}$ In addition, pneumonia remains a serious manifestation of COVID 19 illness. Upper respiratory tract infection symptoms like headache, sore throat, nasal congestion and rhinorrhea also occur in COVID 19 patients. A fair number of cases have been reported with gastrointestinal symptoms of nausea, vomiting, diarrhea and anosmia with taste disturbances. ${ }^{5,13}$ Moderate to severe disease can result in hemoptysis, dyspnea and multiorgan dysfunction. ${ }^{14}$

Patients may have a history of exposure and/or travel to an individual and/or area of an outbreak of COVID 19, respectively. However, at present, this component of clinical assessment may not impact/limit the screening, diagnosis, medical management and therapeutic interventions for COVID 19 patients, as many may present without a travel and/or exposure history as more community transmission is occurring (Figure 3 ).

The clinical presentation may vary in extremes of ages and states of immunosuppression i.e. children and elderly can present with atypical presentations such as hypothermia instead of high-grade fever, delirium, falls, acute decline in functional status, worsening of pre-existing medical conditions, unexplained fatigue and multisystem inflammatory syndrome in children and adolescents with clinical features coinciding with toxic shock syndrome and Kawasaki disease. ${ }^{13}$

There are no reported classic physical findings in COVID 19 illness. However, it is recommended that the clinicians should be aware of the respiratory and hemodynamic indicators of disease severity. These include shock and respiratory distress with ARDS.

\section{Risk Factors for Disease Severity}

Risk factors for severe disease include advanced age with comorbidities such as cardiovascular disease including hypertension, diabetes mellitus, chronic lung disease, stroke, smoking, malignancy, advanced chronic kidney disease, liver disease, obesity and immunosuppression. ${ }^{5,15}$

\section{Immune Responses}

The natural development of immunity after COVID-19 infection is a graduated process typically requiring up to 2 weeks. ${ }^{16}$ This broadly involves innate and adaptive responses. The immediate response against most infections is with innate immunity utilizing macrophages, neutrophils and dendritic cells to slow the infection and thus preventing the symptom onset. Subsequently, developing adaptive responses including antibody production and generation of T-lymphocytes, i.e., the humoral and cellular immune response, respectively. The combined effect of both humoral and cellular immunity helps to reduce the viral progression and its elimination from the body (Figure 4). ${ }^{16}$

Two immunoglobulins against SARS-CoV-2 infection can be detected by laboratory tests namely, neutralizing antibodies (Nabs) and spike-binding antibodies. ${ }^{18}$ These tend to appear 10-15 days post-infection. However, $30 \%$ of infected patients recovered without the development of NAbs even after 2 weeks of infection suggesting that $\mathrm{T}$-cells and cytokine production, other than antibody production plays a vital role in fighting against COVID 


\section{Amir and Prebtani}

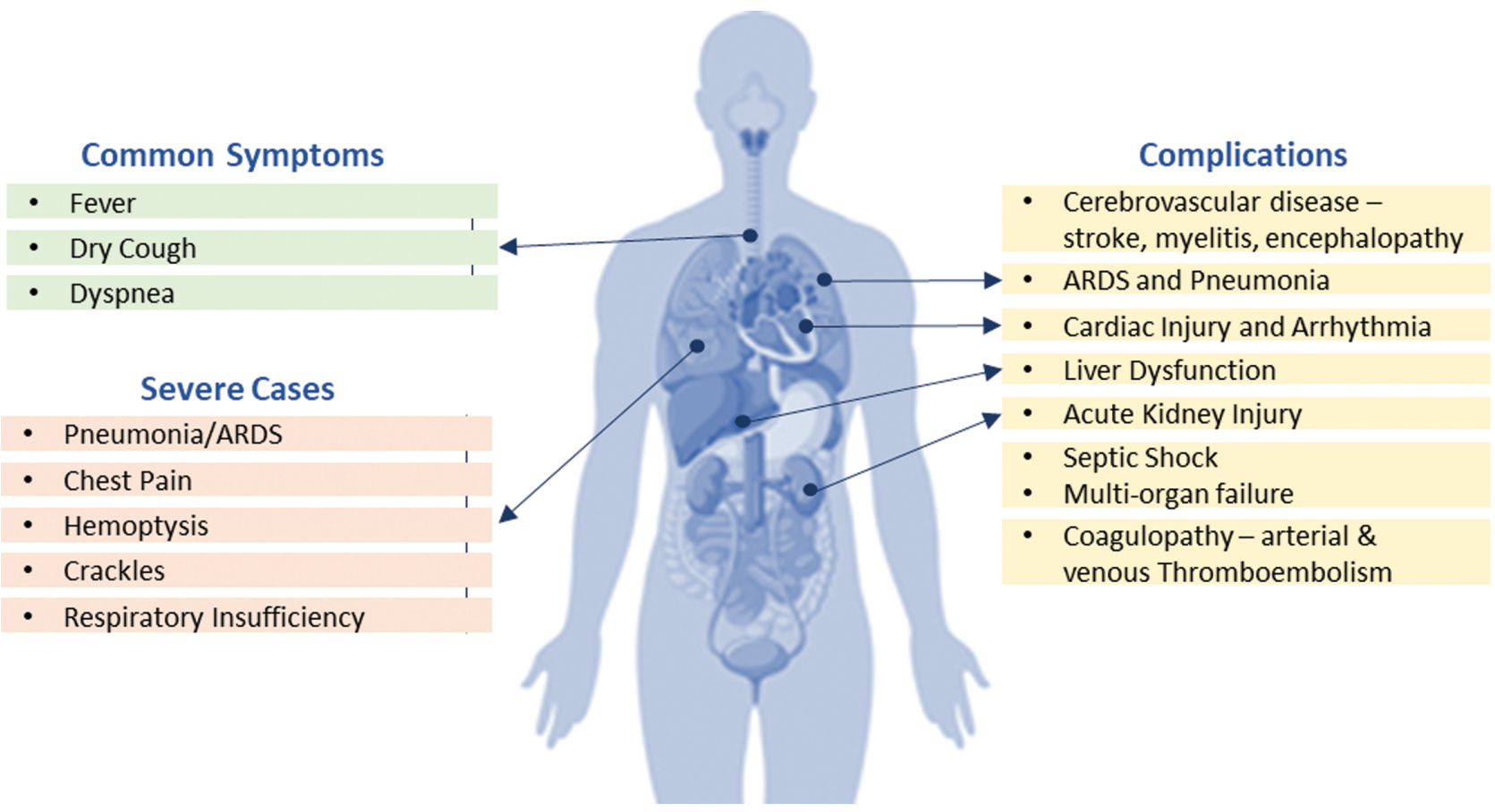

Figure 3. Symptoms and complications of COVID-19.

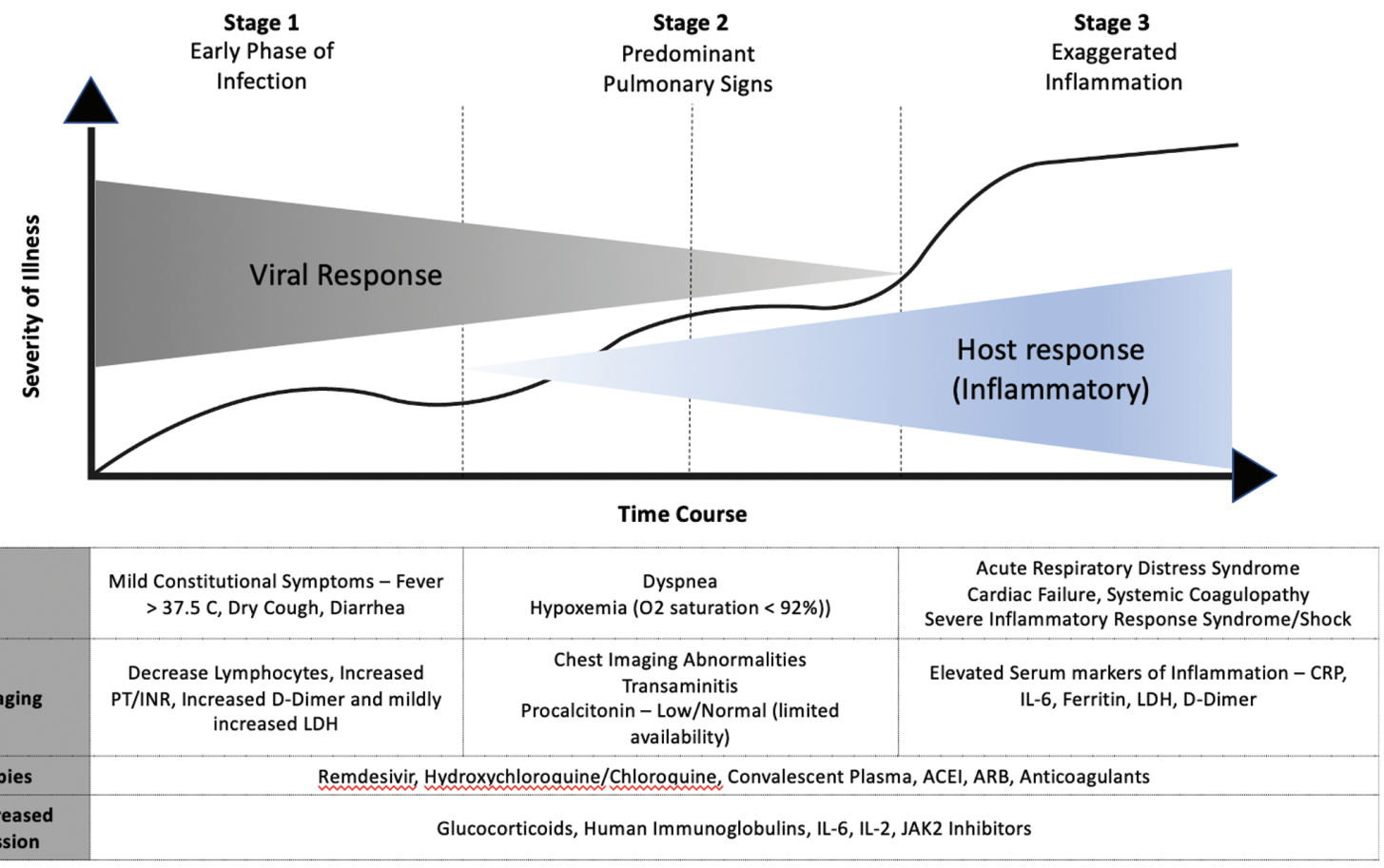

Figure 4. Proposed staging of COVID 19 illness. Adapted from: Siddiqi, et al. ${ }^{17}$ 
19 infection. It was observed that the middle-aged and elderly patients had increased NAbs titers than younger patients. ${ }^{18}$ The higher NAbs titers did not corelate with the lymphocyte count, however corresponded to the C-reactive protein (CRP) levels, further revealing that the humoral immune response plays a vital role in recovery when cellular responses are compromised. ${ }^{18}$

The accuracy for antibody testing including immunodiagnostic testing, needs further evidence to avoid possible false positive or negative results in terms of diagnosis and confirming immunity and sorting out whether the results could be due to other common coronaviruses causing the "common cold".

\section{Clinical Suspicion and Diagnostic Testing}

Diagnostic COVID-19 testing should be offered to patients with an increased risk of having illness based on clinical presentation, especially if high risk or presentation is severe and those at risk for infection who may risk others. These include hospitalized patients, patients undergoing aerosol-generating medical procedures (AGMPs), individuals in a long-term care facility or assisted living facility, healthcare and essential workers in public who have symptoms or have been exposed without protection, caregivers for COVID 19 patients and pregnant women in $3^{\text {rd }}$ trimester who have symptoms or have been exposed. All clinicians should be aware of atypical presentations and should consider testing especially in elderly and children with no other explanation for the symptoms and signs.

The confirmatory test for COVID 19 is the polymerase chain reaction (PCR) or real-time PCR of respiratory tract specimens, from nasopharyngeal swab (NPS) specimens in non-intubated patients and lower respiratory tract specimens in intubated patients. ${ }^{19}$ The latter includes non-induced sputum, specimens from endotracheal aspirates (ETAs) or bronchoalveolar lavage (BAL). Any individual who tests positive is considered a confirmed case of COVID-19 irrespective of the clinical sign/ symptoms and should be isolated following Infection prevention and control (IPAC) guidelines. ${ }^{20}$

The sensitivity of the NPS is up to $95 \%$ during the first 5 days of the symptom onset and drops to 70\% after 5-7 days of symptom onset with illness progression and pneumonia where lower respiratory tract specimens (sputum, ETAs/BAL) may be more diagnostic at later and severe stages of illness. ${ }^{21,22}$ It is crucial to understand the diagnostic limitations of NPS testing, which may result in false negatives, especially when the viral load in upper respiratory tract is low i.e., very early or very late in the disease phase, intermittent shedding and technical errors in sampling. ${ }^{22,23}$ In patients who deteriorate clinically despite negative NPS PCR should consider undergoing lower respiratory tract specimen testing to avoid the false negative results if possible under AGM precautions if clinically indicated. ${ }^{22}$

\section{Guide to Diagnostic Testing}

There are four considerations before ordering diagnostic testing i.e. COVID-19 testing only versus full respiratory viral panel testing (Table 1). These include the patient type i.e., healthy without comorbidities or immunocompromized or with comorbidities, secondly their symptom type such as typical or atypical o, inhospital /admitted or outpatient, and asymptomatic high-risk population (e.g., residents of LTC, neonates and health care workers).

\section{Blood Tests}

Laboratory investigations for COVID 19 includes complete blood count, which shows leukopenia, lymphopenia and thrombocytopenia. Elevated serum markers for infection and inflammation such as CRP and ferritin along with, elevated liver and cardiac enzymes. ${ }^{5}$ Thrombosis markers including D-Dimers, $\mathrm{PT} / \mathrm{INR}$, aPTT, and fibrinogen levels are reported to be higher than upper limit of normal (ULN) along with mild to moderate thrombocytopenia in severe COVID 19. Rising levels of D-Dimers and lymphopenia are associated with increased mortality. ${ }^{5}$

\section{Imaging}

Radiologic imaging of the chest may reveal features consistent with viral pneumonia such as bilateral ground glass appearance. Chest X-ray may appear normal in 50-60\% of COVID 19 cases. $^{24}$ Computerized tomography (CT) scan, if indicated, shows bilateral ground glass opacification with or without consolidation with predilection to right lower lobe and peripheral more than central lung involvement. ${ }^{5} \mathrm{CT}$ scan is sensitive but not specific for COVID 19 disease findings and should be used judiciously and only if alternative diagnoses are suspected to exposure risk and resources. ${ }^{5,24}$

\section{Differential Diagnosis}

The overlapping diagnosis for COVID 19 illness frequently includes other pulmonary infections such as influenza, common cold, other viral and bacterial pneumonias caused by other respiratory pathogens (Parainfluenza, Metapneumoviruses, Mycoplasma Pneumoniae and Pneumocystis Carinii Pneumonial Pneumocystis Jirovecii Pneumonia) ${ }^{25}$ As COVID-19 illness cannot be differentiated from other respiratory conditions, travel or contact history remains an important clue. ${ }^{5}$ Practitioners should keep in mind other causes for respiratory decompensation such as pulmonary embolism, congestive heart failure, asthma and COPD.

\section{Assessment}

Our aim for management of COVID 19 is to control the spread of infection and disease progression to further reduce the morbidity and mortality in COVID 19 patients. 
Table 1. Considerations Before Ordering Diagnostic Testing

\section{Full Viral Respiratory Panel}

a) Typical Symptoms

- All inpatients/or being admitted

\section{Full Viral Respiratory Panel}

a) Atypical Symptoms-unexplained

- All inpatient and out-patient if:

i) Immunocompromized

ii) Comorbidities

iii) Neonates $<3 \mathrm{mo}$

iv) From respiratory outbreak ward with unknown pathogen

Rationale: Impact antibiotic choices with influenza treatment decisions requiring admission for resp concerns and virus identification in outbreak facilities for outpatients

\section{COVID-19 ONLY Test}

a) Atypical/Mild symptoms

- Healthy patients

- Outpatients/Being discharged:

i) HCW and household contacts of HCW

ii) Residents or working in communal settings (LTC/shelters/ remote and indigenous communities et...C)

iii) Essential workers

iv) Cross-border workers

Most low risk outpatients do not require testing for COVID 19 or NPS b) Asymptomatic individuals

- From LTC or ward with COVID 19 outbreak

- Neonates whose mom COVID $19+$ ve

- Request by IPAC for contact racing/outbreak management

- Chronic AGMP on day 8-14 to consider stopping N95 use

- Screen 24-48 hrs before planned AGMP if indicated*

- Transfer to or from LTC*

* These asymptomatic patients do not need isolation unless test positive

Rationale: Knowing COVID 19 status has public health and IPAC implications.

Patients with mild or asymptomatic infection can be managed at home with adequate isolation protocols. Management for these individuals should preferably be via telemedicine and should be centered around prevention of infection transmission as well as monitoring for disease progression. The latter can be fulfilled by educating the patients for red flags of respiratory distress i.e. difficulty breathing, high-grade fever not controlled by antipyretics. Inadequate home care and home isolation with clinical deterioration should prompt hospitalization.

Hospitalized patients with worsening clinical status should be transferred to intensive care unit (ICU). This includes severe pneumonia with a respiratory rate $>30$ breaths $/ \mathrm{min}$, severe respiratory distress with inadequate oxygenation on $\mathrm{FiO} 2>0.50$ and $\mathrm{spO}_{2}</=93 \%$. Severe complications like septic shock and ARDS are additional criteria for critical care.

A multi-disciplinary approach for managing all hospitalized patients is recommended in consultation with public health authorities. Specialist referrals should be considered where appropriate including specialists in infectious disease, internal medicine, pulmonology, and critical care.

\section{Treatment}

The mainstay of therapy for COVID 19 disease is supportive with goals to ensure adequate oxygenation and hemodynamic stability. This could be best achieved by close monitoring for vital signs (BP, HR, respiratory rate), pulse oximetry for hypoxemia $\left(\mathrm{spO}_{2}\right)$, quick sequential organ assessment qSOFA for multiorgan dysfunction, cardiac dysfunction along with clinical worsening to respiratory failure.

\section{Oxygenation}

In cases of severe COVID 19 illness, supportive care remains the mainstay of treatment with immediate supplemental oxygen therapy if $\mathrm{SpO}_{2}<90 \%{ }^{26,27}$ Oxygen administration could be achieved by nasal canula up to 6 litres/min (non-humidified low flow) or Venturi mask FiO2 0.50 or up to 10 litres/min. Target oxygen levels should be maintained between $92-96 \%$ in adults and $88-92 \%$ for carbon dioxide retainers. ${ }^{11}$ Maintenance targets for oxygen therapy in pregnant patients should be $>/=92-95 \%$ and $>/=94 \%$ in children. ${ }^{11}$ If the above-mentioned methods fail to maintain the target oxygen levels, endotracheal intubation should be considered by experienced personnel following strict airborne isolation precautions. ${ }^{26}$ Airway management and oxygen therapy with $\mathrm{spO}_{2} 92-96 \%$ is suggested in adults with signs of respiratory distress, shock and convulsions. ${ }^{11}$

Certain methods for oxygen administration are not recommended for management of COVID 19 patients due to increased risk for aerosolization unless a negative pressure room and high-efficiency particulate air filters (HEPA) are available. ${ }^{26}$ These include non-invasive ventilation (CPAP/Bi-PAP) and high 
Table 2. Epidemiological Comparison of Respiratory Viral Infections

\begin{tabular}{|c|c|c|c|c|}
\hline \multirow{2}{*}{\begin{tabular}{|c|} 
Disease \\
Responsible Microbe
\end{tabular}} & Flu & SARS & MERS & COVID -19 \\
\hline & & & & \\
\hline $\begin{array}{l}\text { Basic reproductive } \\
\text { Number } \mathbf{R}\end{array}$ & 1.3 & 3 & $0.3-0.8 \%$ & $2-2.5 \%$ \\
\hline Case Fatality Rate CFR & $0.05-0.1 \%$ & $9.6-11 \%$ & $34.4 \%$ & $1-14 \%$ \\
\hline Incubation Period & 1-4 Days & 2-7 Days & 6 Days & 4-14 Days \\
\hline Hospitalization Rate & $2.0 \%$ & Most Cases & Most Cases & $19 \%$ \\
\hline Community Attack Rate & $10-20 \%$ & $10-60 \%$ & $4-13 \%$ & $30-40 \%$ \\
\hline Annual Infected & 1 Billion & 8098 (2003) & 420 & N/A (in process) \\
\hline Annual Infected-US & 10 - 45 Million & $8(2003)$ & 2 (in 2014) & N/A (in process) \\
\hline Annual Deaths - US & $10,000-60,000$ & None (since 2003) & None (since 2014) & N/A (in process) \\
\hline
\end{tabular}

Source: Akiko Iwasaki / Yale University / BioRender.

flow nasal cannula (HFNC) oxygen. Fans and nebulized therapy should also be avoided to reduce aerosolization.

It is important to recognize the severe hypoxemic respiratory failure in a patient with severe COVID 19 illness also known as ARDS. It is identified when a patient in respiratory distress is failing to maintain target oxygen levels despite standard, optimal oxygen therapy. Here early endotracheal intubation is recommended as best practice (following airborne isolation protocols). For adult patients requiring mechanical ventilation, use of lower tidal volumes (4-8ml/kg estimated body weight) instead of higher $(>8 \mathrm{~mL} / \mathrm{kg}$ estimated body weight $)$ and lower inspiratory pressures (plateau pressure $<30 \mathrm{~cm}$ of $\mathrm{H}_{2} \mathrm{O}$ ) is recommended to reduce the work of breathing in ARDS. ${ }^{26,27}$ Adult patients with moderate to severe ARDS receiving mechanical ventilatory support, prone ventilation for 12-16 hours a day is recommended. ${ }^{11}$ Higher positive end expiratory (PEEP) is suggested than lower PEEP pressures to avoid atelecttrauma and increasing alveolar recruitment. ${ }^{11}$ Intermittent use of neuromuscular blockage as per need instead of continuous infusion is recommended to allow protective lung ventilation in patients on ventilatory support ${ }^{11,26}$ by limiting the risk of asynchrony-related alveolar collapse and reduction in systemic and lung inflammation. ${ }^{28}$

\section{Role of Corticosterioids}

Until recently, low-quality evidence has been reported for the use of glucocorticoids in reducing mortality and duration of mechanical ventilation in severe COVID 19 with associated
ARDS, and very low-quality evidence for reduced length of hospital stay with little or no impact on ICU stay.

A recent, yet to be peer reviewed study, the RECOVERY trial showed improved survival in ventilated patients and those on oxygen during the course of severe illness as noted in the section on potential therapies and vaccines.

Glucocorticoid use should be considered in patients with refractory shock and other compelling medical indications (e.g. known adrenal insufficiency, other inflammatory disease states requiring their use). ${ }^{29}$

Furthermore, use of convalescent plasma, other specific therapies and proposed antivirals for COVID-19 illness have no proven role yet outside the setting of a clinical trial. ${ }^{29}$

\section{Proning}

The application of supplemental oxygen is augmented by awake self proning of COVID-19 patients without respiratory distress. ${ }^{30}$ It has demonstrated improved oxygen saturation in these patients after the first 5 minutes of proning, by relieving tension in the lungs as well as reducing pulmonary vascular resistance and right heart pressures further alleviating hypoxemia. However, the duration of this effect is not known. ${ }^{30}$ Prone ventilation is recommended for 12-16 hours per day for improved respiratory status.

\section{Hemodynamic Support}

Hemodynamic stability and conservative and cautious fluid management are also important components in care for COVID-19 patients. Cautious fluid administration with balanced crystalloids 


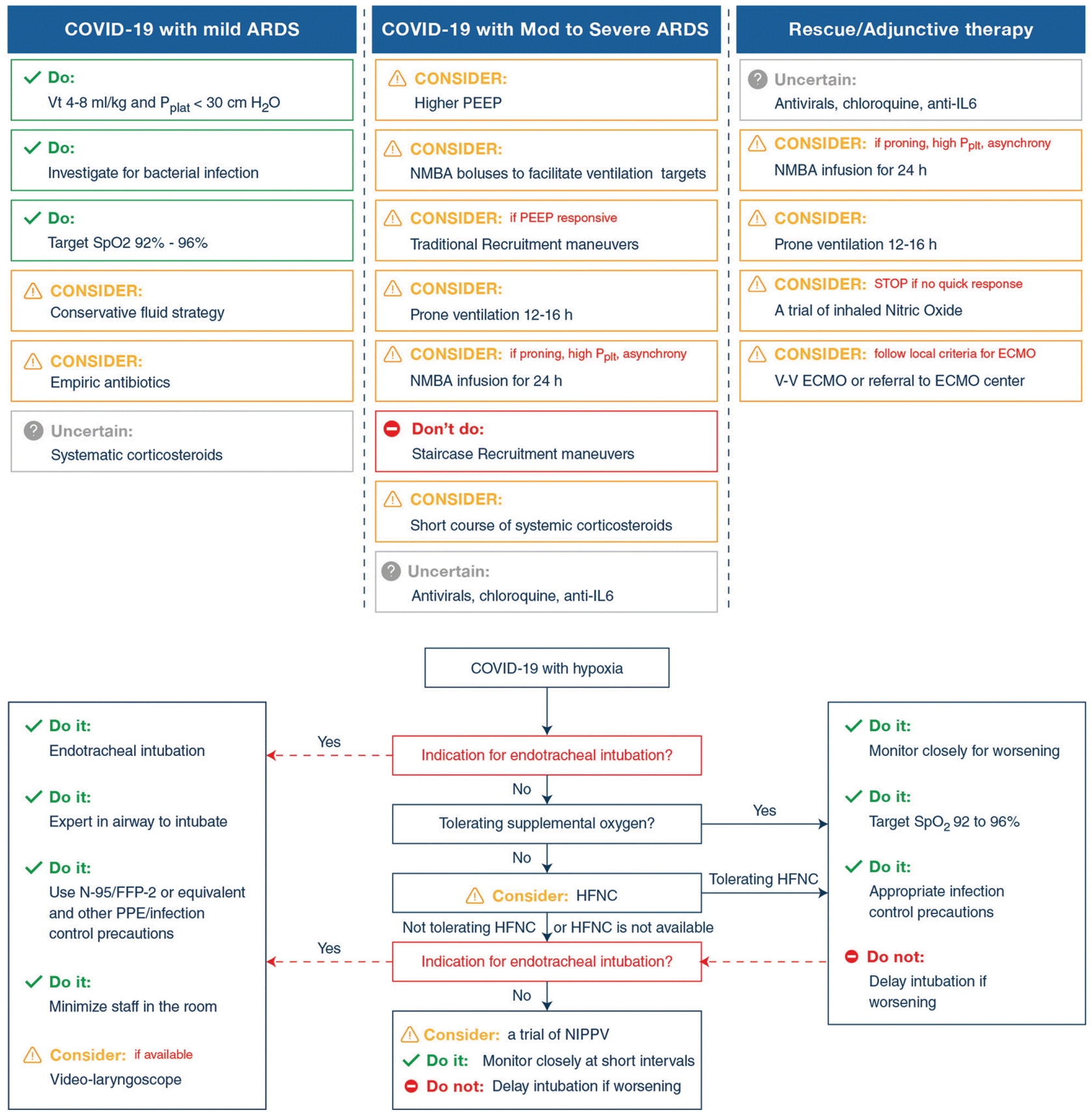

Figure 5. Management of critically ill adults with COVID 19.

Adapted from Alhazzani et al 2020.26

is recommended in the absence of signs and symptoms of hemodynamic shock due to the risk of pulmonary edema. ${ }^{26}$ Norepinephrine is considered as a first-line agent for managing shock. In circumstances where norepinephrine is not available and intravenous fluid administration fails to achieve adequate tissue perfusion, vasopressin and epinephrine can be used as an alternative to norepinephrine. ${ }^{26}$ In addition, vasopressin may be used as a second line agent if a target mean arterial pressure (60-65 $\mathrm{mm}$ of $\mathrm{Hg}$ ) cannot be achieved. ${ }^{27}$ Dopamine is usually not recommended. ${ }^{26}$

Pearl: Avoid transfusion of blood products in the absence of active, major bleeding in COVID 19 patients. ${ }^{31}$ Transfusion with goals of rectifying hemostatic laboratory parameters could result in transfusion reactions, hence detrimental. ${ }^{32}$ 


\section{Co-infections}

Treating co-infections is the cornerstone in management of severe COVID-19 illness. Broad-spectrum antimicrobials should be administered within one hour of presentation with sepsis during the illness if bacterial/viral co-infection is suspected. ${ }^{26,33}$ Use of empiric antimicrobials should be adjusted and/or discontinued according to clinical assessment and results of microbiology. Consider the empiric use of neuraminidase inhibitor (Oseltamivir/ Tamiflu) therapy for potential seasonal influenza in patients with severe COVID-19 or at risk in influenza season. ${ }^{33}$

\section{Goals of Care}

Goals of care discussion including code status should be done by a healthcare professional with the patient and/or family during the initial encounter to avoid the surge state of critical disease and limited resources (ICU, ventilators). ${ }^{34}$ This should be done with an empathetic and sensitive approach. Usual recommendations for palliative care of COVID 19 patients if considered palliative.

\section{Potential Therapies and Vaccines}

Spread of the COVID-19 global pandemic has prompted many clinical and human trials in search for potential specific therapies. These include antivirals (Remdesivir, Lopinavir-Ritonavir + Interferon beta-1b + Ribavirin), immunosuppressive agents (IL-6 antagonist-Tocilizumab) anti-malarials (Chloroquine/ hydroxychloroquine), antibiotics (azithromycin), colchicine and corticosteroids. ${ }^{35}$ More recently, convalescent plasma with antibodies from recovered patients is also being studied as a possible therapeutic option for COVID 19. ${ }^{36,37}$ The definitive results to implement in clinical care are pending based on efficacy and safety. Vaccine development is also in progress. Currently, Remdesivir is being 'considered' for emergency use as standard of care for COVID 19 in the United States of America. ${ }^{38}$

In a recent study, yet to be peer reviewed, by Horby et al, the Dexamethasone arm of the RECOVERY (Randomized Evaluation of COVid-19 thERapY) clinical trial was halted in early June 2020 since sufficient patients had been enrolled to establish a benefit. 2104 in-patients were randomized to receive dexamethasone $6 \mathrm{mg}$ once per day (either by mouth or by intravenous injection) for ten days compared to 4321 patients to usual care alone. Among the in-patients who received usual care alone, 28-day mortality was highest in those who required ventilation (41\%), intermediate in those patients who required oxygen only (25\%), and lowest among those who did not require any respiratory intervention (13\%). Dexamethasone reduced deaths by one-third in ventilated patients (rate ratio 0.65 [ $95 \%$ confidence interval 0.48 to 0.88 ]; $\mathrm{p}=0.0003$ ) and by one fifth in other patients receiving oxygen only $(0.80$ [0.67 to 0.96$] ; p=0.0021)$. There was no benefit among those patients who did not require respiratory support (1.22 [0.86 to 1.75]; $\mathrm{p}=0.14$ ). Based on these results, 1 death would be prevented by treatment of around 8 ventilated patients or around 25 patients requiring oxygen alone. Dexamethasone, an inexpensive readily available drug is the first drug to show improved survival in COVID-19 albeit in this study. Follow-up was complete for over $94 \%$ of participants.

\section{Cardiovascular Patients \\ Renin Angiotensin Aldosterone System (RAAS) and COVID-19}

SARS-CoV-2 which causes COVID 19 illness, gains human cell entry via angiotensin converting enzyme receptor 2 (ACE2) and results in down-regulation of these receptors on cell surfaces after the initial engagement of SARS-CoV-2 spike protein. This process of ACE2 receptor down-regulation is thought to initiate the inflammatory cascade, in turn increasing angiotensin 2 levels and activation of Renin Angiotensin Aldosterone System (RAAS), consequently causing acute lung injury. ${ }^{39}$ Conversely, the restoration of ACE2 through recombinant ACE administration showed reversal of severe lung injury in a few preclinical models. ${ }^{40}$ It appears that the RAAS blockade has perhaps a beneficial role rather than harmful effect in COVID-19, but this has yet to be proven.

According to a small study, patients with COVID-19 who had elevated levels of Angiotensin 2 had corelated viral loads and extent of lung injury. ${ }^{3}$ Various clinical trials are in progress to assess the beneficial effect of RAAS modulation with recombinant human ACE2 and angiotensin receptor blocker (ARB) Losartan in COVID-19 with its potential role in preventing organ system injury. $^{41}$

\section{USE of RAAS blockers in COVID 19}

Based on recent evidence, there has been no harmful association of ACEi or ARBs with in-patient mortality or morbidity in the context of COVID-19 infection. ${ }^{42}$ Inhibitors of RAAS (ACEI, ARBs, \& ANRIs) should be continued in patients who are at risk, being evaluated or confirmed with COVID-19 infection. ${ }^{43}$ These should be discontinued only if advised by the responsible physician or for justified medical reasons such a hypotension, acute kidney injury and hyperkalemia. ${ }^{44}$

Moreover, patients with cardiac disease and renal disease should take acetaminophen instead of Non-steroidal anti-inflammatory drugs (NSAIDS) to avoid deterioration in cardiovascular and renal status (congestive heart failure, hypertension, acute kidney injury). Preferred use of acetaminophen over NSAIDS is recommended for fever and myalgias, however, if already on NSAIDS, patients should consult their physician for ongoing use. The use of low-dose aspirin use for underlying cardiovascular disease should be continued. ${ }^{44}$ 


\section{Pregnancy}

Pregnant patients receive similar supportive therapy as nonpregnant adults. Intrapartum care and mode of delivery should be determined by obstetrical indication and patient preference. Cesarean delivery is only recommended for medical and/ or obstetrical reasons and not for COVID-19 solely. To date, there is little evidence to support vertical transmission from mother to neonate. ${ }^{45}$ While caring for postpartum women, it is recommended to avoid breast feeding until mother has recovered from COVID-19 illness or is considered not to have the infection and that the mother should be isolated from the neonate until she is no longer potentially infectious. ${ }^{46,47}$

Despite the above, women who strongly choose to breast feed should practice hand and respiratory hygiene, and use surgical mask if isolation precautions are not followed, and additionally while providing infant care.

\section{Patients with Human Immunodeficiency Virus}

Course of COVID-19 does not differ in patients with human immunodeficiency virus (HIV) than patients without HIV according to available data. ${ }^{48}$ Recommendations for management of HIV patients who develop COVID-19 do not differ from standard protocols with additional caution in poorly controlled $\mathrm{HIV}^{48}$ Empiric addition of and switching to lopinavir-ritonavir (for possible efficacy against or protection from SARS-CoV-2) is not recommended outside of a clinical trial. ${ }^{48}$

\section{Complications and Prognosis}

As mentioned earlier, there are various risk factors that result in COVID-19 disease severity. Many patients with COVID-19 can progress rapidly from an asymptomatic and non-severe phase to critical disease resulting in complications.

\section{Respiratory Injury}

ARDS remains the major and most frequent manifestation of COVID-19 and can develop shortly after the onset of dyspnea Figure 6 (Figure 3 in the link). Injury mechanisms involve immune and inflammatory responses with subsequent endothelial damage resulting in disrupted vaso-regulation, ventilation perfusion mismatch contributing primarily to initial hypoxemia, further promoting the process of thrombogenesis. ${ }^{49}$ However, some patients might have mild lung injury, initially with good compliance despite poor oxygenation with resulting high minute ventilation. These patients are not overly dyspneic and may not deteriorate to ARDS. ${ }^{50}$

\section{Cardiovascular Injury}

COVID 19 illness has been associated with cardiac injury in one quarter of hospitalized patients. ${ }^{31}$ especially if requiring intensive care result resulting in myocarditis and heart failure with subsequent cardiac arrythmias. Laboratory evidence of higher levels of troponin and brain natriuretic peptides have been associated with disease severity, reaching peak levels at 2-3 weeks after symptom onset. Periodic measurements of these cardiac biomarkers may help in risk stratification for COVID-19 related myocardial demise and consequent ventricular arrythmias. ${ }^{31}$

The acute nature of COVID-19 illness, like any other illness, may precipitate higher cardiometabolic demand contributing to the acute cardiac manifestations even in the absence of underlying coronary artery disease. In addition, cardiac injury is known to be associated with higher in-hospital mortality. ${ }^{17}$ At least $40-60 \%$ of deaths in COVID-19 patients are somewhat attributed to heart failure. ${ }^{31}$ Sustained ventricular arrythmias may occur in $17 \%$ of patients with a predilection for patients requiring intensive care.

The exact mechanism of cardiac pathology in COVID-19 requires further exploration, however it is evident that cardiac consequences are more frequent in those with pre-existing comorbidities like hypertension and coronary artery disease as well as older age.

\section{Neurological Injury}

Neurological abnormalities are occasionally reported in COVID-19 cases. They range from subtle neurological signs and symptoms like severe fatigue and myalgias, trigeminal neuralgia, and complete/severe anosmia, to severe neurologic manifestations such as acute cerebrovascular disease especially large vessel stroke in young individuals, encephalitis, ataxia, myelitis, impaired consciousness and skeletal muscle injury. ${ }^{53}$ A retrospective study from COVID-19 outbreak in Wuhan showed 5\% incidence of stroke among hospitalized patients, with youngest patient of age 55. Isolation precautions including physical distancing resulting and reluctance to hospital visit may contribute to poor clinical outcomes in patients with neurologic deficits. ${ }^{54}$

Older age and more severe form of COVID-19 illness have a higher likelihood for cerebrovascular injury. ${ }^{53}$ The progression to cerebrovascular disease is a negative prognostic factor in the course of the illness.

\section{Coagulopathy/Thrombosis}

COVID-19 patients are more susceptible to vascular thrombosis, both arterial and venous thromboembolism (VTE) (venous > arterial) resembling heparin-induced thrombocytopenia (HIT) and/or disseminated intravascular coagulation (DIC) ${ }^{56}$ Overall, 20-50\% of COVID-19 patients requiring hospital admission have shown laboratory evidence of coagulopathy. Typical pattern 
includes a higher D-dimer (4-6 times higher than ULN), mildly prolonged prothrombin time (15-16 seconds)/INR and aPTT, mild to moderate thrombocytopenia (platelet count 100-150 $\times 10^{9} / \mathrm{L}$ ). It is recommended to repeat these three parameters every 2-3 days in hospitalized patients with severe COVID-19. Moreover, later in the disease, a drop in the fibrinogen levels $(<2 \mathrm{~g} / \mathrm{L}[5.88])$ is also noted however it is not uncommon to have a normal or high fibrinogen level. ${ }^{32}$

Coagulopathy associated with COVID-19 seems to be prothrombotic with no bleeding complications. ${ }^{32}$ This could be well explained by the exaggerated inflammatory response, hypoxia and DIC. A recent study found $31 \%$ incidence of thrombotic complications in ICU cases despite thromboprophylaxis. ${ }^{57}$ The higher rates of thromboembolism in COVID-19 has led to a proposal of thromboprophylaxis in all hospitalized patients with need for increased dose under special circumstances, in the absence of contraindications to anticoagulant use. ${ }^{58}$ For those with contraindications mechanical prophylaxis with intermittent pneumatic compression devices is recommended. ${ }^{11}$

Standard prophylactic dosing for all patients is advised with recommended adjustments in certain circumstances based on expert recommendations, although there is no randomized control trial data yet. The following applies to non-pregnancy adults with normal renal function. Increase doses by $50 \%$ of parenteral anticoagulation for patients with estimated body weight $(\mathrm{EBW})>100 \mathrm{~kg}$ or $\mathrm{BMI}>35$ (e.g., Dalteparin 7,500 IU daily or enoxaparin $30 \mathrm{mg}$ twice daily or enoxaparin $40 \mathrm{mg}$ once daily). Increase the dose by $100 \%$ in patients if EBW $>140 \mathrm{~kg}$ or BMI $>40$, D- Dimer $>5,000$ or additional risk factors e.g. prior VTE, active malignancy and ICU admission (e.g., Dalteparin $5,000 \mathrm{IU}$ bid or or enoxaparin $40 \mathrm{mg}$ bid or tinzaparin 10,000 IU daily) are recommended. Empiric use of therapeutic doses of low molecular weight heparin (LMWH) preferably over unfractioned heparin (UFH) is recommended in cases of clinical or respiratory decompensation where diagnostic testing for pulmonary embolism is difficult. ${ }^{58}$ Anticoagulation with LMWH appears to have a better prognosis in severe COVID-19 patients who have elevated D-Dimers $(>3.0 \mathrm{~mol} / \mathrm{mL}) .{ }^{59}$ In patients with renal insufficiency, dose adjustments will be required based on eGFR. If there is a concern regarding HIT, fondaparinaux may be used. Warfarin should be avoided along with direct oral anticoagulants (DOACs) due to possible drug interactions if clinical trial drugs are likely to be administered Figure 7 (see Figure 2 in the link).

\section{Immune System Injury}

Some patients have laboratory evidence of exaggerated inflammatory response, similar to cytokine storm, resulting in persistent fevers, elevated inflammatory serum markers (D-dimers, ferritin) and proinflammatory cytokines. ${ }^{5}$ These laboratory findings have been shown to increase the critical disease and fatality in COVID-19 illness in particular, lymphopenia and increase in D-dimers (Figure 8$).^{5}$

\section{Multisystem Inflammatory Syndrome}

An exaggerated inflammatory response has been recently reported in some cases of COVID-19 in pediatric population (age 0-19 years), leading to multiorgan dysfunction and shock with positive diagnostic test for COVID-19. Clinical picture in this age range had overlapping features of toxic shock syndrome and atypical Kawasaki disease. They manifest as prolonged fever, features suggestive of muco-cutaneous inflammatory signs in oral cavity, eyes, hands and feet as well as gastrointestinal and cardiac involvement. Laboratory parameters were consistent with signs of inflammation in the absence of other possible etiology and severe COVID-19 illness. Currently, these cases are managed with anti-inflammatory and supportive care. More vigorous studies are needed to develop a clear underlying pathology, if truly causal and its possible therapeutic options.

\section{Others}

Sepsis, shock, secondary infections (bacterial and fungal) and multiorgan dysfunction involving the liver, kidney, and pancreatic damage are reported as other possible complications of COVID-19. ${ }^{61,62}$

More evidence is needed to clarify if the organ damage is a direct result of virus itself, exaggerated inflammatory response, or is the consequence of severe illness or treatment.

\section{Prognosis}

Overall, recovery from infection on a short and long-term basis is observed in 8 out of 10 patients. Up to $14 \%$ patients require hospitalization and up to $5 \%$ ventilation support. ${ }^{63}$

Globally the case fatality rate is between $1-14 \%$ and may differ with time and among various regions depending on age, other comorbidities, resources, and accurate reporting of data. ${ }^{12}$ There is limited data available to estimate the infection fatality rate with the possibility of many undiagnosed cases.

Advanced age continues to be a consistent predictor of mortality in ICU patients with severe disease. ${ }^{65}$ Data shows that both cardiac injury and cerebrovascular disease have been associated with poor clinical outcomes and high mortality in COVID-19 patients.

\section{Prevention}

COVID-19 illness is caused by human coronavirus, primarily spread through infected person via respiratory droplet, close prolonged contact, and touching virus-contaminated surfaces. 


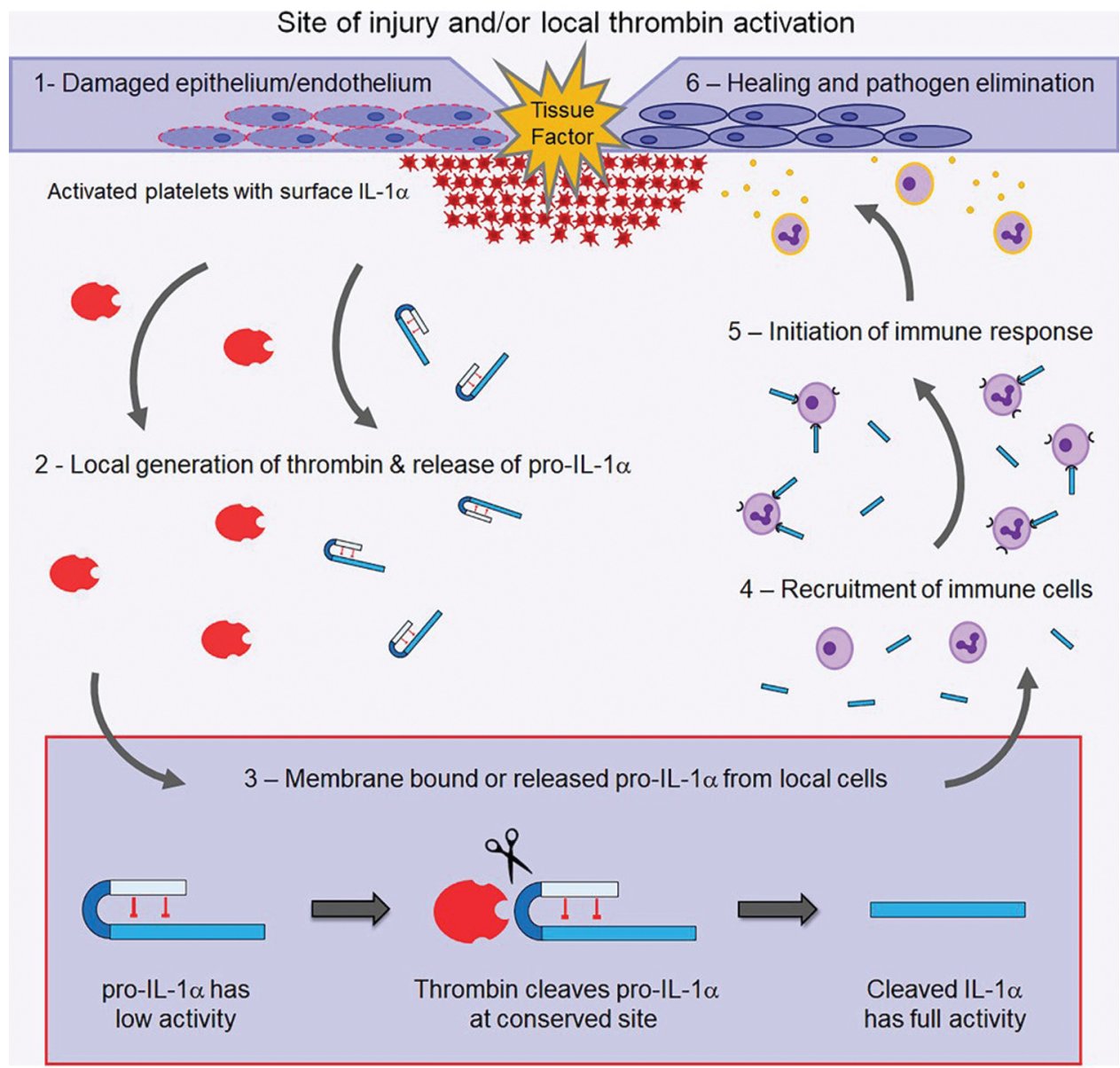

Figure 8. Direct linkage between immune responses and thrombosis.

Reprinted from Burzynski et al 2019. ${ }^{60}$

As discussed earlier, there has been no primary prevention i.e. vaccine for COVID-19, therefore it is recommended to follow strict isolation and prevention precautions advised by the local public health authorities.

\section{Advise to General Public}

Based on the current knowledge and experience through the COVID-19 global pandemic, it is recommended to practice physical distancing along with proper hand and respiratory hygiene as the main strategy in preventing the infection and its spread in healthy population. This includes avoiding unnecessary gatherings, staying at home except for critical needs such as resupplying food and medications while ensuring safe distancing in public (stay 2 meters 6 feet apart). In addition, hand washing with soap and water for at least 20 seconds is recommended whereas, alcohol-based (at least $60 \%$ alcohol) hand sanitizer use is advised until next possible hand washing. ${ }^{66,67}$ The use of facemasks in public has not been evaluated systematically, their use has not been shown to be protective against the infection however, they can be used as a measure to reduce the spread to others where it is difficult to ensure physical distancing. ${ }^{67,68}$ Having said that, facemasks are not a substitute for physical distancing. ${ }^{67}$

\section{Household Members and Caregivers}

Wearing facemasks, gloves and gown is recommended when caring for a COVID-19 patient. Removal and proper disposal of the protective gears is advised upon leaving the patients room. Ensure hand hygiene as mentioned above after all contact with COVID-19 patients. Do not share personal items such as towels, dishes, utensils before proper cleaning. ${ }^{69}$ It is suggested to wear gloves when handling dirty laundry and wash laundry and high touching surfaces frequently. ${ }^{69}$ Most importantly, restrict contact to minimum number of caregivers. ${ }^{70}$

\section{Healthcare Settings}

All the healthcare facilities should follow strict isolation precautions according to IPAC protocols for all suspected cases of COVID-19. Standard contact and droplet precautions should be applicable for all persons entering patients room including 
wearing a facemask. Routine practices should include practicing hand hygiene as above, implementing respiratory hygiene, maintaining distance of 2 meters between a suspected coughing COVID-19 patient and another patient. Ensure enhanced PPE with standard transmission precautions while performing or exposure to high-risk aerosolization procedures. ${ }^{10}$

\section{Personal Protective Equipment}

PPEs are defined as specialized clothing or equipment worn by an employee for protection against infectious material. Some types of PPE include gloves, gowns/aprons, mask/respirators, goggles, and face shields for the protection of mainly face including eyes, mouth and nose. ${ }^{71}$ The PPE selection and use rely upon certain factors like type of exposure and isolation precaution, task appropriateness and proper size for fit. The utilization of protective apparel should be used with an aim to reduce the infection spread with proper donning and doffing practices with proper and immediate disposal following patient interaction. It is recommended to don before encounter with suspected or confirmed COVID-19 case. ${ }^{10}$ Performing hand and respiratory hygiene before and after patient handling is strongly recommended. The only recommendation for reusing or extending the PPE use after initial utilization is during contingency or crisis capacity with lacking supplies. ${ }^{72}$

\section{Aerosol-Generating Medical Procedures}

A list of medical interventions including procedures and certain maneuvers e.g. physical proning of the patient, cardiopulmonary resuscitation with endotracheal intubation, open deep tracheal suctioning, bronchoscopy HFNC oxygen and non-invasive positive pressure ventilation could be potential cause of aerosolization resulting in increased viral transmissibility. ${ }^{10,73}$ While actively performing or assisting these procedures it is recommended to use enhanced PPE devices to avoid the probable increased risk of infection. ${ }^{73}$ Enhanced PPE during these high-risk activities include N95 respirator masks, full face shields, level 2 gown and gloves with measures for droplet as well as contact precautions. It is advised to use the PPE with precautionary measures for at least 15 minutes in operating rooms and 30 minutes in other rooms to allow air clearance of infectious droplets. ${ }^{73}$ Moreover, aerosol-generating medical procedures (AGMPS) on ICU patients should be conducted in a negative pressure environment as a best $_{\text {practice. }}{ }^{26}$

\section{Discontinuation of Transmission-Based Precautions}

There are two main strategies to help decide the time of isolation discontinuation for infection control in symptomatic COVID-19 patients, for both, home isolation and hospitalized individuals, whereas asymptomatic cases without subsequent COVID-19 illness may discontinue isolation precautions 14 days after the first day of positive diagnostic testing. ${ }^{74}$

These include test-based strategy and non-test-based strategy. Test-based strategy is preferred for patients requiring prolonged hospitalization and patients with immunosuppression as both these groups may have longer duration of viral shedding hence more contagious than others. ${ }^{75}$ The latter group includes patients with inherited immunodeficiency, those being treated with immunosuppressive agents, transplant recipients and HIV patients with poorly controlled infection. ${ }^{75}$ Residents of the longterm care facility are considered high risk for severe disease. Patient transfer to such facility necessitates close caution and should be offered test-based approach before discontinuation of isolation measures. ${ }^{74,75}$

\section{Non-Test-Based Strategy}

Fever resolution without anti-pyretic use along with improvement in respiratory symptoms such as cough and shortness of breath for 72 hours and at least 14 days have passed since the first day of symptom onset may be eligible for isolation discontinuation. ${ }^{74,75}$ Absence of cough is not necessary for isolation discontinuation in patients with chronic cough and in those with post-infectious reactive airways. ${ }^{74}$

\section{Test-Based Strategy}

Negative PCR results from 2 consecutive tests, 24 hours apart before discontinuation of isolation precaution along with fever resolution without anti-pyretic use and improvement in respiratory symptoms such as cough and shortness of breath may be eligible for isolation discontinuation. ${ }^{74,75}$ Absence of cough is not necessary for isolation discontinuation in patients with chronic cough and in those with post-infectious reactive airways. ${ }^{74}$

\section{Conclusion}

COVID-19 is a declared health emergency that has affected over 200 regions globally and remains a constant threat to health safety. COVID-19 illness is a rapidly spreading highly infectious novel Coronavirus formerly known as severe acute respiratory syndrome, SARS-CoV-2. Its infectivity during the incubation period and asymptomatic transmission makes it difficult to control its transmissibility through conventional IPAC methods. Currently, quarantine and isolation precautions are the only effective and proven interventions to reduce the infectious rate.

Along with typical clinical signs and symptoms (mainly respiratory and constitutional), COVID-19 also presents atypically particularly in children and elderly. COVID-19 has its sequalae on almost every organ system in particular, the respiratory, cardiac, 
hematological (thrombotic), and immune system. A multisystem inflammatory syndrome affecting children and adolescents is also reported in pediatric cases of severe COVID-19.

PCR using a respiratory specimen is the standard diagnostic test for COVID-19. Positive antibody titers do not confer definite immunity in all against a re-infection.

Numerous clinical trials are taking place with several pharmacological agents, convalescent plasma and vaccine development with many pending results with none so far have been of proven benefit unequivocally.

At present, management is supportive including maintaining adequate oxygenation and hemodynamic support and treatment of preventing of its associated complications.

Ongoing research during this COVID-19 global pandemic will further help, uncover facts regarding pathogenesis, disease spectrum, and evidence-based treatment and prevention modalities in the reduction of future waves of outbreaks further eliminating its disease burden in the society.

\section{References}

1. Chan JFW, Lau SKP, To KKW, Cheng VCC, Woo PCY, Yuen K-Y. Middle East respiratory syndrome coronavirus: another zoonotic betacoronavirus causing SARS-like disease. Clinical Microbiol Reviews 2015 Apr;28(2):465-522.

2. Zhou P, Yang X-L, Wang X-G, Hu B, Zhang L, Zhang W, et al. A pneumonia outbreak associated with a new coronavirus of probable bat origin. Nature 2020 Mar;579(7798):270-3.

3. Vaduganathan M, Vardeny O, Michel T, McMurray JJV, Pfeffer MA, Solomon SD. Renin-Angiotensin-Aldosterone System Inhibitors in Patients with Covid-19. N Engl J Med 2020 Apr;382(17):1653-9. doi/10.1056/ NEJMsr2005760

4. World health Organization. Modes of transmission of virus causing COVID-19: implications for IPC precaution recommendations. Available from: https://www.who.int/news-room/commentaries/detail/modes-oftransmission-of-virus-causing-covid-19-implications-for-ipc-precautionrecommendations [Accessed 11 May 2020]

5. Kenneth McIntosh. Coronavirus disease 2019 (COVID-19): Epidemiology, virology, clinical features, diagnosis, and prevention. 2020. Available from: https://www.uptodate.com/contents/coronavirus-disease-2019-covid-19epidemiology-virology-clinical-features-diagnosis-and-prevention [Accessed 12 May 2020]

6. Wölfel R, Corman VM, Guggemos W, Seilmaier M, Zange S, Müller MA, et al. Virological assessment of hospitalized patients with COVID-2019. Nature 2020 Apr;1-5.

7. Gandhi M, Yokoe DS, Havlir DV. Asymptomatic Transmission, the Achilles' Heel of Current Strategies to Control Covid-19. N Engl Jo Med 2020 Apr. doi. org/10.1056/NEJMe2009758

8. Delamater PL, Street EJ, Leslie TF, Yang YT, Jacobsen KH. Complexity of the Basic Reproduction Number (R0). Emerg Infect Dis J 2019 Jan;25(1):1-4.

9. Centre of Infectious Disease Research and Policy. COVID-19: The CIDRAP Viewpoint. Available from: https://www.cidrap.umn.edu/sites/default/files/ public/downloads/cidrap-covid19-viewpoint-part1_0.pdf [Accessed 11 May 2020]

10. Ontario Agency for Health Protection and Promotion (Public health Ontario). Infection Prevention and Control recommendations for use of personal protective equipment for care of individuals with suspect or confirmed COVID-19. Toronto, Ontario. 2020. Available from: https://www. publichealthontario.ca/-/media/documents/ncov/updated-ipac-measurescovid-19.pdf?la=en [Accessed 12 May 2020]

11. World Health Organization. Clinical management of severe acute respiratory infection when COVID-19 is suspected. Available from: https://www.who. int/publications-detail/clinical-management-of-severe-acute-respiratoryinfection-when-novel-coronavirus-(ncov)-infection-is-suspected [Accessed 15 April 2020]

12. Worldometer. Coronavirus Mortality Rate (COVID-19). Available from: https://www.worldometers.info/coronavirus/coronavirus-death-rate/\#ref-13 [Accessed 11 May 2020]

13. Government of Ontario Ministry of Health and Long-Term Care. MERS$\mathrm{CoV}$ (Novel Coronavirus) - Ministry Programs - Health Care Professionals - MOHLTC. Available from: http://www.health.gov.on.ca/en/pro/programs/ publichealth/coronavirus/2019_guidance.aspx\#symptoms [Accessed 10 May 2020]

14. Huang C, Wang Y, Li X, Ren L, Zhao J, Hu Y, et al. Clinical features of patients infected with 2019 novel coronavirus in Wuhan, China. Lancet 2020 Feb 1;395(10223):497-506.

15. Patanavanich R, Glantz SA. Smoking is Associated with COVID-19 Progression: A Meta-Analysis. medRxiv [Internet]. 2020 Apr;2020.04.13.20063669. doi/10.1101/2020.04.13.20063669

16. World Health Organization. Coronavirus disease 2019 (COVID-19) Situation Report - 73. 2020. Available from: https://www.who.int/docs/default-source/ coronaviruse/situation-reports/20200402-sitrep-73-covid-19.pdf [Accessed 10 May 2020]

17. Siddiqi HK, Mehra MR. COVID-19 illness in native and immunosuppressed states: A clinical-therapeutic staging proposal. J Heart Lung Transplant 2020 May;39(5):405-7.

18. Wu F, Wang A, Liu M, Wang Q, Chen J, Xia S, et al. Neutralizing antibody responses to SARS-CoV-2 in a COVID-19 recovered patient cohort and their implications. medRxiv. 2020 Apr. doi/10.1101/2020.03.30.20047365

19. World Health Organization . Laboratory testing for coronavirus disease (COVID-19) in suspected human cases: interim guidance. 2020. Available from: https://www.who.int/publications-detail/laboratory-testing-for-2019-novelcoronavirus-in-suspected-human-cases-20200117 [Accessed 29 April 2020]

20. World Health Organization. Global surveillance for COVID-19 caused by human infection with COVID-19 virus: interim guidance. 2020. Available from: https://www.who.int/publications-detail/global-surveillance-for-covid19-caused-by-human-infection-with-covid-19-virus-interim-guidance [Accessed 25 April 2020]

21. Hamilton Health Sciences. COVID-19: Safety, Screening \& Reporting. 2020. Available from: http://www.hamiltonhealthsciences.ca/covid19/staffphysician/safety/ [Accessed 12 May 2020]

22. Chuen V, Said H, Shell J, Plaxton W, Ciccotelli W. Diagnosis of COVID-19 by Bronchoalveolar Lavage after Two Negative Nasopharyngeal Swabs. Can J Gen Intern Med 2020 Apr 8;15(2):5-7.

23. Marty FM, Chen K, Verrill KA. How to Obtain a Nasopharyngeal Swab Specimen. N Engl J Med 2020 Apr. doi: 10.1056/NEJMvcm2010260

24. Rubin GD, Ryerson CJ, Haramati LB, Sverzellati N, Kanne JP, Raoof S, et al. The Role of Chest Imaging in Patient Management during the COVID-19 Pandemic: A Multinational Consensus Statement from the Fleischner Society. CHEST 2020 Apr. doi: https://doi.org/10.1016/j.chest.2020.04.003

25. Public Health Ontario. Review of "Differential diagnosis of illness in patients under investigation for the novel coronavirus (SARS-CoV-2), Italy, February 2020". 2020. Available from: https://www.publichealthontario.ca/-/media/ documents/ncov/research-eurosurveill-differential-diagnosis.pdf?la=en [Accessed 13 May 2020]

26. Alhazzani W, Møller MH, Arabi YM, Loeb M, Gong MN, Fan E, et al. Surviving Sepsis Campaign: guidelines on the management of critically ill adults with Coronavirus Disease 2019 (COVID-19). Intens Care Med 2020 May;46(5):854-87. doi:10.1007/s00134-020-06022-5

27. Poston JT, Patel BK, Davis AM. Management of Critically Ill Adults With COVID-19. JAMA 2020 May;323(18):1839-41. 
28. Papazian L, Forel J-M, Gacouin A, Penot-Ragon C, Perrin G, Loundou A, et al. Neuromuscular Blockers in Early Acute Respiratory Distress Syndrome. N Engl J Med 2010 Sep;363(12):1107-16. https://doi.org/10.1056/ NEJMoa1005372

29. Ye Z, Rochwerg B, Wang Y, Adhikari NK, Murthy S, Lamontagne F, et al. Treatment of patients with nonsevere and severe coronavirus disease 2019: an evidence-based guideline. CMAJ 2020 Apr. doi:10.1503/cmaj.200648

30. Caputo ND, Strayer RJ, Levitan R. Early Self-Proning in Awake, Nonintubated Patients in the Emergency Department: A Single ED's Experience during the COVID-19 Pandemic. Acad Emerg Med 2020 Apr;27(5):375-78.

31. Calvillo-Argüelles O, Ross HJ. Cardiac considerations in patients with COVID-19. CMAJ 2020 May. doi/10.1503/cmaj.200562

32. Lee SG, Fralick M, Sholzberg M. Coagulopathy associated with COVID-19. CMAJ 2020 May. doi:10.1503/cmaj.200685

33. Farkas J. COVID-19 - EMCrit Project. The Internet Book of Critical Care. 2020. Available from: https://emcrit.org/wp-content/uploads/2020/03/ COVID-19-EMCrit-Project3-16.pdf [Accessed 01 May 2020]

34. Arya A, Buchman S, Gagnon B, Downar J. Pandemic palliative care: beyond ventilators and saving lives. CMAJ 2020 Apr;192(15):400-4.

35. Canada Health. Vaccines and treatments for COVID-19: List of all COVID 19 clinical trials authorized by Health Canada. 2020. Available from: https:// www.canada.ca/en/health-canada/services/drugs-health-products/covid19clinical-trials/list-authorized-trials.html [Accessed 13 May 2020]

36. Shen C, Wang Z, Zhao F, Yang Y, Li J, Yuan J, et al. Treatment of 5 critically ill patients with COVID-19 with convalescent plasma. JAMA 2020 Apr;323(16):1582-9.

37. Roback JD, Guarner J. Convalescent plasma to treat COVID-19: possibilities and challenges. JAMA 2020 Apr;323(16):1561-2.

38. National Institute of Allergy and Infectious Diseases. NIH Clinical Trial Shows Remdesivir Accelerates Recovery from Advanced COVID-19| NIH 2020. Available from: http://www.niaid.nih.gov/news-events/nih-clinicaltrial-shows-remdesivir-accelerates-recovery-advanced-covid-19 [Accessed 09 May 2020]

39. Bombardini T, Picano E. Angiotensin-converting enzyme 2 as the molecular bridge between epidemiologic and clinical features of COVID-19. Can J Cardiol 2020 May;36(5):784.e1-784.e2.

40. Kai H, Kai M. Interactions of coronaviruses with ACE2, angiotensin II, and RAS inhibitors-lessons from available evidence and insights into COVID-19. Hypertens Res 2020 Apr. https://doi.org/10.1038/ s41440-020-0455-8

41. Vaduganathan M, Vardeny O, Michel T, McMurray JJV, Pfeffer MA, Solomon SD. Renin-angiotensin-aldosterone system inhibitors in patients with Covid-19. N Engl J Med 2020 Apr;382(17):1653-9. doi:10.1056/ NEJMsr2005760

42. Mehra MR, Desai SS, Kuy S, Henry TD, Patel AN. Cardiovascular disease, drug therapy, and mortality in Covid-19. N Engl J Med 2020 May. https://doi. org/10.1056/NEJMoa2007621

43. Jarcho JA, Ingelfinger JR, Hamel MB, D’Agostino RB, Harrington DP. Inhibitors of the renin-angiotensin-aldosterone system and Covid-19. N Engl J Med 2020 May. https://doi.org/10.1056/NEJMe2012924

44. Canadian Cardiovascular Society. Guidance from the CCS COVID-19 rapid response team. 2020. Available from: https://www.ccs.ca/images/ Images_2020/CCS_CHFS_Update_COVID_CV_medications_Mar20.pdf [Accessed 25 April 2020]

45. Chen H, Guo J, Wang C, Luo F, Yu X, Zhang W, et al. Clinical characteristics and intrauterine vertical transmission potential of COVID-19 infection in nine pregnant women: a retrospective review of medical records. Lancet 2020 Jul;395(10226):809-15.

46. Maxwell C, McGeer A, Tai KFY, Sermer M. No. 225-Management guidelines for obstetric patients and neonates born to mothers with suspected or probable severe acute respiratory syndrome (SARS). Jo Obstet Gynaecol Canada 2017 Aug;39(8):130-7.
47. Society of Obstetrics and Gynecology. Updated SOGC Committee Opinion - COVID-19 in Pregnancy. 2020. Available from: https://www.sogc.org/en/ content/featured-news/Updated-SOGC-Committee-Opinion_COVID-19in-Pregnancy.aspx [Accessed 02 May 2020]

48. United States Department of Health and Human Services - AIDSinfo. Interim Guidance for COVID-19 and Persons with HIV COVID-19 and Persons with HIV. Available from: https://aidsinfo.nih.gov/guidelines/html/8/covid-19and-persons-with-hiv--interim-guidance-/554/interim-guidance-for-covid19-and-persons-with-hiv [Accessed 20 April 2020]

49. O’donnell J, Sharif K, Emery P, Bridgewood C, Mcgonagle D. The Immune Mechanisms of Pulmonary Intravascular Coagulopathy in COVID-19 Pneumonia. 2020 May. doi:https://doi.org/10.1016/S2665-9913(20) 30121-1

50. Marini JJ, Gattinoni L. Management of COVID-19 respiratory distress. JAMA 2020 Apr. doi:10.1001/jama.2020.6825

51. McGonagle D, O’Donnell JS, Sharif K, Emery P, Bridgewood C. Immune mechanisms of pulmonary intravascular coagulopathy in COVID-19 pneumonia. Lancet Rheumatol 2020 May. doi:https://doi.org/10.1016/ S2665-9913(20)30121-1

52. Shi S, Qin M, Shen B, Cai Y, Liu T, Yang F, et al. Association of cardiac injury with mortality in hospitalized patients with covid-19 in Wuhan, China. JAMA Cardiol 2020 Mar. doi:10.1001/jamacardio.2020.0950

53. Mao L, Jin H, Wang M, Hu Y, Chen S, He Q, et al. Neurologic manifestations of hospitalized patients with coronavirus disease 2019 in Wuhan, China. JAMA Neurol 2020 Apr. doi:10.1001/jamaneurol.2020.1127

54. Oxley TJ, Mocco J, Majidi S, Kellner CP, Shoirah H, Singh IP, et al. Largevessel stroke as a presenting feature of covid-19 in the young. New N Engl J Med 2020 Apr. https://www.nejm.org/doi/10.1056/NEJMc2009787

55. Helms J, Kremer S, Merdji H, Clere-Jehl R, Schenck M, Kummerlen C, et al. Neurologic reatures in severe SARS-CoV-2 infection. N Engl J Med 2020 Apr. https://www.nejm.org/doi/10.1056/NEJMc2008597

56. Lodigiani C, Iapichino G, Carenzo L, Cecconi M, Ferrazzi P, Sebastian T, et al. Venous and arterial thromboembolic complications in COVID-19 patients admitted to an academic hospital in Milan, Italy. Thrombosis Res [Internet] 2020 Jul;191:9-14.

57. Klok FA, Kruip MJHA, van der Meer NJM, Arbous MS, Gommers DAMPJ, Kant KM, et al. Incidence of thrombotic complications in critically ill ICU patients with COVID-19. Thrombosis Res 2020 Apr. doi: 10.1016/ j.thromres.2020.04.013

58. Bikdeli B, Madhavan MV, Jimenez D, Chuich T, Dreyfus I, Driggin E, et al. COVID-19 and thrombotic or thromboembolic disease: implications for prevention, antithrombotic therapy, and follow-up. J Am Coll Cardiol 2020 Apr. https://doi.org/10.1016/j.jacc.2020.04.031

59. Tang N, Bai H, Chen X, Gong J, Li D, Sun Z. Anticoagulant treatment is associated with decreased mortality in severe coronavirus disease 2019 patients with coagulopathy. J Thrombosis Haemost 2020 Mar;18(5): 1094-9.

60. Burzynski LC, Humphry M, Pyrillou K, Wiggins KA, Chan JNE, Figg N, et al. The coagulation and immune systems are directly linked through the activation of interleukin-1 $\alpha$ by thrombin. Immunity 2019 Apr;50(4): 1033-1042.e6.

61. Wang F, Wang H, Fan J, Zhang Y, Wang H, Zhao Q. Pancreatic injury patterns in patients with COVID-19 pneumonia. Gastroenterology 2020 Apr. doi: https://doi.org/10.1053/ j.gastro.2020.03.055.

62. Micheal W. Smith. Complications of Coronavirus (COVID-19). Available from: https://www.webmd.com/lung/coronavirus-complications [Accessed 04 May 2020]

63. Micheal W. Smith. Coronavirus Recovery. Available from: https://www. webmd.com/lung/covid-recovery-overview [Accessed 11 May 2020]

64. World Health organization. WHO Director-General's opening remarks at the media briefing on COVID-19 - 3 March 2020. Available from: https://www. who.int/dg/speeches/detail/who-director-general-s-opening-remarks-at-themedia-briefing-on-covid-19---3-march-2020 [Accessed 15 may 2020] 
65. Grasselli G, Zangrillo A, Zanella A, Antonelli M, Cabrini L, Castelli A, et al. Baseline characteristics and outcomes of 1591 patients infected with SARS-CoV-2 admitted to ICUs of the Lombardy Region, Italy. JAMA 2020 Apr;323(16):1574-81.

66. World Health Organization. Advice for public. 2020. Available from: https:// www.who.int/emergencies/diseases/novel-coronavirus-2019/advice-forpublic [Accessed 12 May 2020]

67. Canada Public Health Agency. COVID-19: About non-medical masks and face coverings. 2020. Available from: https://www.canada.ca/en/publichealth/services/diseases/2019-novel-coronavirus-infection/prevention-risks/ about-non-medical-masks-face-coverings.html [Accessed 10 May 2020]

68. World Health Organization. Advice on the use of masks in the context of COVID-19. 2020. Available from: https://www.who.int/publications-detail/ advice-on-the-use-of-masks-in-the-community-during-home-care-and-inhealthcare-settings-in-the-context-of-the-novel-coronavirus-(2019-ncov)outbreak [Accessed 05 May 2020]

69. Centers for Disease Control and Prevention. Coronavirus Disease 2019 (COVID-19). 2020. Available from: https://www.cdc.gov/coronavirus/2019ncov/if-you-are-sick/care-for-someone.html [Accessed 29 April 2020]

70. Canada Public Health Agency. How to care for a person with COVID-19 at home: Advice for caregivers [Internet]. 2020. Available from: https://www. canada.ca/en/public-health/services/publications/diseases-conditions/ how-to-care-for-person-with-covid-19-at-home-advice-for-caregivers.html [Accessed 30 April 2020]

71. Centre for Disease Control. Guidance for the Selection and Use of Personal Protective Equipment (PPE) in Healthcare Settings. Available from: https:// www.cdc.gov/hai/prevent/ppe.html [Accessed 11 May 2020]

72. Infectious Diseases Society of America Guidelines on Infection Prevention in Patients with Suspected or Known COVID-19. Available from: https://www. idsociety.org/practice-guideline/covid-19-guideline-infection-prevention/ [Accessed 15 April 2020]

73. London Health Sciences Centre. Guidelines Adult Critical care for Aerosol Generating Medical Procedures (AGMP) for Failed ARI Screen or Unable to Assess or Confirmed COVID-19. 2020. Available from: https://www.lhsc. on.ca/media/8476/download [Accessed 20 April 2020]

74. Ministry of Health Ontario. Ministry of Health COVID-19 Quick Reference Public Health Guidance on Testing and Clearance. 2020. Available from: http://www.health.gov.on.ca/en/pro/programs/publichealth/ coronavirus/2019_guidance.aspx\#guidance [Accessed 14 May 2020]

75. Centre for Disease Control and Prevention. Discontinuation of Transmission-Based Precautions and Disposition of Patients with COVID-19 in Healthcare Settings (Interim Guidance). 2020. Available from: https:// www.cdc.gov/coronavirus/2019-ncov/hcp/disposition-hospitalized-patients. html [Accessed 15 April 2020] 